\title{
Reviewing institutional policies for electronic management of assessment
}

Julie Voce, Department for Educational Research, Lancaster University

j.voce@lancaster.ac.uk

This article is published in Higher Education.

To cite this article:

Voce, J. (2015) Reviewing institutional policies for electronic management of assessment, Higher Education,

69(6), p.915-929. Springer.

The final publication is available at Springer via http://dx.doi.org/10.1007/s10734-014-9813-2

\begin{abstract}
Electronic assignment submission (e-submission) tools, such as those within course management systems (e.g. Blackboard), or systems such as Turnitin, which enable students to submit coursework online are now one of the main centrally-supported institutional tools in Higher Education (HE) in the United Kingdom (UK), however the development of institutional policies for the Electronic Management of Assessment (EMA) has not kept up with the implementation of the technology. This study takes a Critical Discourse Analysis approach to review a selection of EMA policies from UK HE institutions. The results find that the policies are often unclear about the main actors involved in the EMA process and fail to clarify who is responsible for actions. In addition, whilst students feature most frequently in the policies, their role is often back-grounded such that students are not given control of the actions relating to them. The study concludes with guidance aimed at anyone writing their own institutional EMA policy and asserts that policies should be clear about the participants involved and their responsibilities.
\end{abstract}

Keywords: E-submission, E-marking, E-feedback, Electronic Management of Assessment, policy, UK Higher Education 


\title{
Reviewing Institutional Policies for Electronic Management of Assessment
}

Electronic assignment submission (e-submission) tools, such as those within course management systems (e.g. Blackboard) or systems such as Turnitin, which enable students to submit coursework online are now one of the main centrally supported institutional tools in Higher Education (HE) in the United Kingdom (UK). The Universities and Colleges Information Systems Association's (UCISA) biennial Technology Enhanced Learning (TEL) survey of 165 UK HE institutions, reported that 85 of the 98 responding institutions provide centrally supported e-submission tools (Walker, Voce, \& Ahmed, 2012). In addition, the proportion of courses using e-submission has increased over the past five years such that $50 \%$ of institutions reported use of esubmission in over $50 \%$ of their courses (Walker, Voce, \& Jenkins, 2013). However, the development of institutional policies for e-submission, e-marking and e-feedback has not kept up with the implementation of the technology. The Heads of e-Learning Forum (HeLF)'s annual study on the Electronic Management of Assessment (EMA) has consistently reported a lack of institutional policies for EMA (Newland, Martin, Bird, \& Masika, 2013), however respondents indicated that progress was being made in establishing EMA policies. This tallies with findings from the UCISA TEL Survey which reported only $15 \%$ of respondents having an e-assessment/e-submission policy (Walker et al., 2012).

This study takes a Critical Discourse Analysis approach to review a selection of policies for EMA from UK HE institutions to identify the language used and the roles of staff and students. Given the lack of institutional EMA policies, the ultimate aim is to provide guidance to other institutions looking to develop their own EMA policy.

\section{Electronic Management of Assessment}

Newland et al. (2013) defined EMA as being made up of four constituent parts:

\author{
eSubmission - electronic submission of an assignment \\ eMarking - electronic marking (including offline marking eg in Word) \\ eFeedback - electronic feedback (ie text, audio, video but not hard copy) \\ eReturn - electronic return of marks (p. 2)
}

To build on the definitions by Newland et al. (2013) this study considers EMA to relate to the submission of a primarily text based assignment which requires marking by a human, rather than a quiz containing fixed response questions, e.g. multiple choice, that can be automatically marked by a computer system. 
A brief literature review utilising both the Academic Search Complete and the Google Scholar databases retrieved 12 relevant recent studies in the area of EMA. In addition a recent $\mathrm{Jisc}^{1}$ funded programme on Assessment and Feedback provided two further studies relating to EMA (Djordjevic \& Milward, 2012; Ellis \& Reynolds, 2013). Given the widespread presence of e-submission tools reported by the UCISA TEL survey (Walker et al., 2012), these low results imply that EMA is an embedded part of an institution and warrants little research.

Of those studies retrieved, the focus was primarily on the use of e-submission and either e-feedback or e-marking either within a particular cohort of students and/or utilising a particular tool, such as the plagiarism detection software Turnitin (Bridge \& Appleyard, 2008; Buckley \& Cowap, 2013; Dahl, 2007), and have typically explored staff and student attitudes to the use of EMA.

For students, the key benefit of using EMA related to ease of use and the time-saving nature of esubmission over handing in paper-based assignments in person (Bridge \& Appleyard, 2008; Dahl, 2007). In addition Dahl (2007) reported that students preferred receiving electronic feedback and claimed this was surprising as "electronic feedback requires the student to read online rather than receiving a paper copy" (p.179). However, given student preference for e-submission, this preference for receiving electronic feedback is not particularly a surprise. Of those studies which considered student concerns, they related to issues with the receipting system and technical issues with submitting particular media types, such as images (Bridge \& Appleyard, 2008).

Few studies encapsulated staff views on EMA. Buckley and Cowap (2013) highlighted concerns relating to the use of Turnitin and reported that whilst staff liked specific features of Turnitin that made marking quicker and easier, in general they found it took longer to mark online, compared to marking by hand. Ellis and Reynolds (2013) reported that EMA was not popular amongst academic staff due to concerns surrounding emarking and a preference for paper-based marking.

It is surprising that the focus of recent studies continues to be on fairly small-scale usage given that Jones and Behrens (2003) noted this ten years previously. Where there has been some research at the institution level, it has typically related to the roll-out of a home-grown assessment system (Bancroft, Hynd, Dal Santo, \& Reye, 2003; Downton, Glasfurd-Brown, \& Mossop, 2006). One exception is the Jisc funded Online Coursework Management Evaluation (OCME) project (Djordjevic \& Milward, 2012) which reviewed the end-to-end EMA process and produced a set of recommendations for other institutions looking to set up institution-wide EMA.

With reference to policies for EMA, Jones and Behrens (2003) commented that the "policies, procedures and structure of the organisation in which OASM [Online assignment submission and management]

\footnotetext{
${ }^{1}$ Jisc - http://www.jisc.ac.uk/
} 
is used will also influence its evolution" (p. 4) and credited the evolution of EMA within their own institution to organisational policies, amongst other things. Yet they failed to identify which policies benefitted the evolution of EMA and to define what influence is required to encourage staff and students to adopt EMA. In presenting guidance on the implementation of EMA, Gray and Ferrell (2013) highlighted the need for "careful planning to ensure all of the right pieces, relating to people, processes and technology infrastructure, are in place" (Implementing EAM, para. 1) however they neglected to include policies as an important part of implementation. Given the widespread nature of EMA, it could be perceived that policies governing its use are simply not required or that institutions are slow to adapt existing assessment policies. However, as noted by Ellis and Reynolds (2013), assessment strategies in general are under-represented in the literature, so it would seem that there are perhaps no existing assessment strategies or policies to be adapted. Ellis and Reynolds (2013) also commented that institutions were hesitant to adopt EMA strategies due to resistance from academic staff and the implementation of EMA systems that are not reliable and/or robust. Yorke (1998) emphasised the importance of policy for assessment in terms of accountability and providing institutional steer and this importance could be extended to EMA. This study therefore looks at existing EMA policies to understand how the institutional steer is provided and provides guidance for the institutions yet to define their own EMA policy.

The lack of research in the area of EMA policy makes it difficult to utilise an existing theoretical framework for this study. Whilst some of the studies retrieved in the literature review touched on areas related to the implementation of change, this is too wide a field to provide a useful framework for a policy analysis.

\section{Methodology}

Critical Discourse Analysis (CDA) focuses on the relationship between discourse and society such that the language used within a discourse is influenced by the society within which it was created. Discourse is not only "shaped by situations, institutions and social structures, but it also shapes them" (Fairclough, Mulderrig, \& Wodak, 2011, p. 357). The stance taken for this study is that discourse, such as policy documents, is socially influential and that the language used within discourse can reveal social structures and the negotiation of power relationships.

CDA traditionally draws on a number of influences (Fairclough, 2002; Van Dijk, 1993; Wodak \& Meyer, 2009b) and typically takes a problem-oriented approach to the study of discourse (either written, spoken or visual) that combines linguistic and semiotic analysis at the micro-level with social analysis of power relations at the macro-level (Luke, 2002).

As highlighted by Wodak and Meyer (2009a) "CDA does not constitute a well-defined empirical methodology but rather a bulk of approaches with theoretical similarities" (p. 27). Fairclough (2002) also 
commented on the varying approaches to discourse analysis based on the nature of the project; however, he went on to provide a set of guidelines for a three-dimensional analysis:

- Discourse practice - the type of discourse used, the transformations in the discourse, its coherence and the use of other discourses or genres.

- $\quad$ Text - such as the grammar used, cohesion, politeness, ethos, modality, etc.

- $\quad$ Social practice - the social and power relationships within the discourse.

Referring to policy analysis, Ball (2012) highlighted the benefit of utilising discourse analysis for understanding the formation of policy stating that policies are "statements about practice - the way things could or should be - which rest upon, derive from, statements about the world - about the way things are” (p. 22).

CDA has been used effectively in several studies of education strategies and policies (Nolan \& Mayfield, 2008; Smith, 2008; Taylor, 2004; Thomas, 2005) and Rogers, Malancharuvil-Berkes, Mosley, Hui and O’Garro Joseph (2005) highlighted the prevalence of Fairclough's three-dimensional analysis approach in studies using CDA in educational research. CDA is therefore a useful approach for analysing the use of language in EMA policy documents and the power relationships of the actors involved, typically staff and students of the institution.

This study uses the three-dimensional analysis process suggested by Fairclough (2002) with a particular focus on the dimensions of 'Text' and 'Social practice'. To carry out the textual analysis, I have incorporated the use of Halliday’s Systemic Functional Linguistics (SFL) as described by Eggins (1994). SFL complements a Faircloughian approach as it also considers the social context of language creation. Eggins (1994) highlighted the role of SFL as enabling researchers to view language as a "strategic, meaning-making resource" (p.1) and so the role of SFL is therefore to understand the meaning of a text by considering how the people in the text use language and how the language has been structured. This study analyses the use of language within the policy documents with a focus on authority and role of the participants.

\section{Reflexivity}

Rogers et al. (2005) highlighted the role of the educational researcher as being a reflexive one such that the researcher is a member of the community being researched. Pre-existing beliefs, values and assumptions lead to a blurring of the distance and closeness of the researcher. As an e-learning specialist I have a particular interest in EMA and the role of policies to support it, such that I intend to develop a policy for my own institution as a result of this research. This could lead to interpretational bias as I may identify areas either present or missing that I feel should be included within an EMA policy. 


\section{Sample}

In CDA, there is no specific approach to the collection of discourses for the sample (Wodak \& Meyer, 2009a) and "the choice of appropriate methods (data collection and mode of analysis) depends on what one is investigating" (Fairclough et al., 2011, pp. 358-359). The sample of policy documents used within this study was obtained by consulting the Heads of E-learning Forum (HeLF) who represent key individuals in the field of TEL and would be expected to be aware of relevant policies relating to the use of EMA in their institutions. In addition, a simple web search using Google with the terms "online submission policy" and "e-submission policy" was carried out which generated one further policy document. It should be noted that some respondents from HeLF indicated that their institution does not have a specific policy relating to EMA, but that individual departments have included statements about EMA in their own strategy/policy documents. Only institution-wide policy documents have been considered for this study.

In considering the policies found, I utilised the following definition of a policy to aid with reviewing the relevance of the document to this study:

\section{A Policy is a concise formal statement of principles which indicate how the University will act in a particular area of its operation eg in relation to academic promotion or to racism. In short, policy provides members of the University with the approved way of operating in relation to a particular matter. (The University of Newcastle Australia, 2013)}

Six policy documents were considered, however two were not specifically called policies. One was a roadmap leading to the development of a policy and the other was a set of e-submission guidelines to support a more general assessment policy. The roadmap document did not adequately meet the definition of a policy as it was more of a position paper to highlight the reasons for utilising e-submission and to consider various options available to the institution. The document would inevitably lead to the development of a policy, but for the purposes of this paper, it did not meet the requirements. The e-submission guidelines did, however, meet the definition of a policy, despite being called guidelines and so it was felt that this document should be included in the sample. Five policies were therefore reviewed for this study. Newland et al. (2013) reported only 13 of 52 responding institutions have an institution-wide e-submission policy, so five policies would account for a third of their population size and is therefore an appropriate sample size given the timescales for this study. The policies have been anonymised and assigned a number from 1 to 5 . Where quotes are used from the policies, the nomenclature of P1-P5 is used to indicate which policy the quote comes from.

Table 1 provides an overview of the types of institution for each policy. It is notable that the policies retrieved were all from institutions considered to be 'new universities', which are defined as institutions granted university status through the 1992 Further and Higher Education Act. The mission group affiliation is also 
provided as the majority of UK universities are aligned to a 'mission group' such that members of a group share common traits such as origin, ethos and aims. It should be noted that there no policies from members of the Russell Group, which comprises the elite research-focussed UK universities.

Table 1

Overview of the institution to which each policy belongs

\begin{tabular}{cllc}
\hline Policy & Institution type & Mission group & No. students \\
\hline P1 & New university & GuildHE $^{2}$ & 9,000 \\
P2 & New university (former polytechnic) & University Alliance & 24,000 \\
P3 & New university & GuildHE & 6,000 \\
P4 & New university & GuildHE & 11,000 \\
P5 & New university (former polytechnic) & Million $^{4}$ & 23,000 \\
\hline
\end{tabular}

\section{Data Analysis}

This section primary considers the Discourse and Text elements of Fairclough's (2002) threedimensional analysis by analysing the five policy documents in terms of:

- $\quad$ Structural analysis - document layout, coherence, use of sections and the topics covered.

- Linguistic analysis - primarily the types of clauses used and the use of modality.

\section{Structural Analysis}

Table 2

Overview of key features identified in the structural analysis

\begin{tabular}{cccccccc}
\hline Policy & $\begin{array}{c}\text { Length } \\
\text { (words) }\end{array}$ & Author type & $\begin{array}{c}\text { Title } \\
\text { page }\end{array}$ & $\begin{array}{c}\text { Institution } \\
\text { logo }\end{array}$ & $\begin{array}{c}\text { Publication } \\
\text { date }\end{array}$ & $\begin{array}{c}\text { Review } \\
\text { date }\end{array}$ & $\begin{array}{c}\text { Version } \\
\text { number }\end{array}$ \\
\hline P1 & 1,284 & Department & Yes & Yes & Yes & Yes & No \\
P2 & 461 & Individual & Yes & Yes & Yes & Yes & No \\
P3 & 1,088 & Department & Yes & Yes & Yes & No & No \\
P4 & 1,371 & Department & Yes & Yes & Yes & No & Yes \\
P5 & 569 & None given & No & Yes & No & No & No \\
\hline
\end{tabular}

The number of words used in the policies ranged from 461 words (Policy 2) to 1,371 words (Policy 4). The policies appeared formal in nature through the inclusion of items such as a title page with the document

\footnotetext{
${ }^{2}$ GuildHE - http://guildhe.ac.uk/

${ }^{3}$ University Alliance - http://www.unialliance.ac.uk/

${ }^{4}$ Million+ - http://www.millionplus.ac.uk/
} 
title, an institutional logo and the date of publication; only Policy 5 did not include a separate title page or the date of publication. In addition the incorporation of a table of information in Policies 1, 2 and 4, assisted with the feeling of formality. The table of information typically included the author, date of creation/modification, approval granted and review date and was situated at the beginning (Policies 2 and 4) or end (Policy 1) of the document.

Of the four policies which stated an author, only one was written by an individual, the rest were all attributed to named institutional groups such as the "Academic Quality Directorate" (Policy 1) and "Learning \& Teaching Development" (Policy 3).

Policies 1, 3, 4 and 5 all started with an introduction section, which outlined the purpose of the policy and all of the policies provided an explanation of the target level of usage of EMA within the institution. Sharpe, Benfield and Francis (2006) reported that it is common to find this sort of target at the beginning of strategic implementation documents and so it is not unusual to find targets in these EMA policies. Policies 1 and 5 set a target of $75 \%$ of coursework to be submitted electronically, however Policies 2, 3 and 4 state that 'all coursework' needs to be submitted online, with the caveat that it meets the criteria specified in the policy document. This criteria either specified the conditions under which items can be submitted:

From September 2012, [Institution] policy requires, as a minimum expectation, all coursework items meeting the following criteria to be submitted electronically:

- a single file

- in Word or pdfformat

- up to 2000 words or equivalent. (P2)

or related to noted exceptions which cannot be submitted online:

It is recognised that exceptions do exist, and e-submission does not apply to:

- creative coursework (e.g. for art and design courses)

- $\quad$ some types of portfolios presentations

- $\quad$ some types of group work (P3)

Policies 1 and 3 highlighted the benefits of EMA to various stakeholders using bulleted lists describing items that EMA would enable, for example:

Students:

- $\quad$ can submit assignments without having to be physically present on campus (P1) 
Policy 5 suggested reasons for using EMA; however, the language used was different, such that the policy referred to the removal of "a significant number of difficulties for our students" rather than calling them benefits.

Policies 1, 3, 4 and 5 all followed the introduction section with a set of guidelines for the different stages of the EMA process. Policies 2, 3 and 4 all finished with a section which detailed where key stakeholders, such as staff and students, could obtain further information, training or support.

Policy 2 did not have such a complex structure and was simply split into two key parts: the first stated the EMA expectations and clarified points about what the policy does and does not include; the second provided implementation guidelines.

Policy 4 contained the most number of sections and used headings to clearly delineate the different topics, which made it much easier to find topics such as extenuating circumstances which were more hidden in the other policies.

As standalone policy documents, the coherence within the texts was generally good and required little external reading. The policies were targeted at individuals within an HE environment who would be aware of the various processes surrounding assessment. Where necessary the policies used either web-links or names of other documents to refer the reader to additional sources:

\section{DSE [Display Screen Equipment] users who have not undertaken a workplace risk assessment should refer to the guidance at [link provided] (P4)}

\section{RELATED POLICIES \& DOCUMENTS}

- Policy on the Marking of Anonymised Coursework

· [Institution] Safety Code of Practice 20, Display Screen Equipment (P2)

\section{Linguistic Analysis}

The aim of a policy is to define the actions that need to be undertaken by the institution for the enactment of the policy (The University of Newcastle Australia, 2013). This section focuses on the linguistic features of the text to determine how authoritative the policy is when it comes to defining the actions and providing the necessary institutional steer.

Considering the overall use of language within the policies, the majority of the clauses are declarative such that they make a statement, which is unsurprising given the role of the policies is to provide information. 
The Blackboard Assignment Handler will continue to be the recommended tool for electronic submission. (P2)

Ferrell (2012) reported that institutional strategy and policy documents tend to have a procedural feel to them, and this is certainly the case for these policies which use declarative clauses to describe the procedures surrounding EMA. The use of the passive voice is particularly common which means that the person responsible for certain actions is not always mentioned and could cause confusion as to who carries out a particular action.

Second marking will be conducted in accordance with parameters set in the Assessment Policy and made available via Turnitin GradeMark. (P5)

Work marked online will be actioned and returned to students in accordance with the University's Assessment Practice policy. (P3)

There is limited use of the imperative in the form of commands, for example:

contact the Academic Quality Directorate. (P1)

Policies 2 and 4 do not use the imperative at all and Policies 1 and 5 only have one imperative clause. Policy 3 makes the most use of the imperative in its closing section whereby a series of conditional statements incorporating the imperative is used to advise the reader what to do should they require further information or support, for example:

If you are unsure of your Faculty's processes and procedures for handling electronic assignment submission, marking and feedback, please contact your line manager. (P3)

Conditional statements are used in all of the policies to describe what should be done in particular scenarios:

Where academic staff elect to print submissions, they must provide students with a coversheet available through Blackboard Help. (P2)

Where teaching teams feel unable to mark online then assessments submitted online can be downloaded and printed for marking. (P4)

Modality is a linguistic construct used to express either possibility or likelihood of something occurring (known as modalization) or an obligation/necessity (known as modulation) (Eggins, 1994). Modal clauses typically, but not exclusively, use the modal auxiliaries: must, should, could and would. Modality is used in the policies to express an obligation/necessity and the policies demonstrated varying degrees of modulation: "high: must/required to, median: should/supposed to, low: may/allowed to" (Eggins, 1994, p. 189). Table 3 shows the frequency of use of the different levels of modulation within each policy. 
Table 3

Frequency of each level of modulation used in each policy

\begin{tabular}{lcccccc}
\hline & P1 & P2 & P3 & P4 & P5 & Total \\
\hline High & 3 & 4 & 1 & 2 & 0 & 10 \\
Median & 7 & 3 & 8 & 9 & 1 & 28 \\
Low & 6 & 2 & 0 & 2 & 0 & 10 \\
\hline Total & 16 & 9 & 9 & 13 & 1 & 48 \\
\hline
\end{tabular}

Policies 3 and 4 make little use of high and low modulation in favour of median modulation, for example:

Guidance should be provided by the Unit Leader in the Assessment Brief. (P4)

marking should be completed using the online general comments area ... (P3)

Policy 2 makes the most use of high modulation compared with the other modulation types found within the same document. This policy document is much shorter than the others, so perhaps this higher frequency is due to being more direct in its use of language:

Electronic submissions for summative assessment must be anonymised in compliance with [Institution's] Marking of Anonymised Coursework Policy. (P2)

Policy 5 uses the least modulation with only one modulated clause and instead relies on use of the future passive tense to describe what actions need to be taken, but never identifies the person who should be carrying out the action:

Second marking will be conducted in accordance with parameters set in the Assessment Policy and made available via Turnitin GradeMark. (P5)

Provisions will need to be made to enable students who wish to submit their work late and claim extenuation. (P5)

This use of the future passive is found in several policies and would appear to be used to background obligational meanings through the use of 'will be' and 'is expected to', which act to assign responsibility rather than enforce the action.

Heads of Subject will be responsible for ensuring staff have been trained. (P1)

Module Leaders/markers are expected to undertake the marking of the assignments electronically if they are submitted electronically. (P3) 
The use of 'is/are encouraged to' would appear to be an alternative to a low modulation:

Module Leaders/markers are encouraged to handle the marking of the assignments

electronically if they are received by e-submission, and to mark on-screen. (P1)

In the description of benefits in Policies 1 and 3, the subject of each clause is clearly identified by using the name of a particular stakeholder as a heading followed by a number of bullet points listing the benefits for that stakeholder. The bullet points generally start with the use of the word 'can' acting as a dynamic modality implying the 'ability' to do something. For example in Policies 1 and 3 it is stated that students:

can submit assignments without having to be physically present on campus

can remain anonymous $(P 1)$

Often, when the policies indicate an obligation, they fail to identify the actor in the clause. This could mean that no one then takes that action upon themselves, which is a concern when the action relates to students as these policies tend to be aimed at staff rather than students.

Students should be made aware that any grades given by the VLE are indicative ... (P3)

Students should be encouraged to submit drafts to the system ... (P4)

Training on e-submission will be made available to students at induction ... (P1)

\section{Discussion}

This section discusses the social practice aspect of Fairclough's (2002) three-dimensional analysis by considering the participants identified in the policies and the possible social and power relationships within the discourse.

In the processes associated with EMA there are many participants with the key roles being enacted by the students who submit the work, the academic staff who mark the work and the administrative staff who support the e-submission and e-return processes. Between them, the policies identified a number of participants and these have been split into the following categories, some of which are further split into sub-categories with reference to individuals and to particular teams or units.

Table 4

Different categories of actors found within the policy documents and the total number of references.

\begin{tabular}{llc}
\hline Category & Words used & No. references \\
\hline Students & Students (general), Disabled students, Student debtors & 48 \\
Academic staff & $\begin{array}{l}\text { Individuals: Academic staff, Tutors, Markers, Module Leaders, } \\
\text { Teaching staff, Academic managers }\end{array}$
\end{tabular}


Teams: Programme Teams, Unit teams, Teaching teams.

Support staff Individuals: Administrative staff, Support staff

Teams: Professional Services, Academic Services, Academic Support Unit, Academic Enhancement Unit, Learning and Information Services (LIS), Technology Enhanced Learning Team, Learning Technology Unit, Student Support.

Senior staff Faculty Deans, Senior School Registrars, Senior School Administrators, Heads of Subject

Institutional University, Faculty, Department, QSEC Committee $\quad 16$

Other External Examiners, DSE [Display Screen Equipment] users

\section{Students}

In total there are 45 references to students, however in two-thirds of cases they are not considered to be the actor in the clause, whereby an actor is defined as "the constituent of the clause who does the deed or performs the action" (Eggins, 1994, p. 231). Students tend to be acted upon in the policies; however, the actor is unknown in the majority of cases, which could lead to ambiguity as to who is ultimately responsible for carrying out the action:

Training on e-submission will be made available to students at induction and online throughout their course. $(P 1)$

Work marked online will be actioned and returned to students in accordance with the University's Assessment Practice policy. (P4)

Where students are the actor in a clause, their role primarily relates to the act of submitting assignments, which is to be expected:

Students will submit assessments using an online assignment cover sheet ... (P4)

Students:

- $\quad$ can submit assignments without having to be physically present on campus (P2)

Compared with the categories for staff, there is less diversity amongst the references to students, with only two sub-categories identified: disabled students and student debtors. Both of these are used in Policy 4 to explain lack of provision for these types of student:

There has been no requirement to make additional provision for disabled students (P4)

Any hard copy assignments submitted to faculty help desks by student debtors will not be marked. (P4) 
In addition, there is frequent use of the word 'student' in relation to the work or assignments that are acted on by the processes described in the policies, for example:

e-submission is any facility for online submission of student work ... (P3)

Where student work has been marked online ... (P1)

In terms of the power relationship, students are generally seen to be acted upon, although it is not always clear by whom. Despite several policies claiming that the policy is relevant to students, the use of the passive makes it difficult for students to clearly determine their actions and responsibilities. This implies that the policies are not as 'student-facing' as the institutions might believe them to be. The policies could make this clearer for both staff and students by either including an actor in the clause or re-wording the actions to put the student as the subject.

\section{Staff}

With 48 references across the five policies, staff are the most represented category of participants; the references have been split into three categories relating to academic staff, support staff and senior staff.

In terms of academic staff there are six different terms used, of which the term 'academic staff' appears most frequently and in all policies. It is not entirely clear why some policies use more specific terms such as 'Module Leaders', 'markers' and 'tutors' when in most cases 'academic staff' would appear to be appropriate. For example, 'academic staff' would be expected to carry out marking, and yet in the following examples we see the more specific words of 'Module Leaders' and 'markers' used. This could be due to specific roles within an institution such that a marker might not be a member of academic staff.

Module Leaders/markers are expected to undertake the marking of the assignments electronically if they are submitted electronically. (P3)

Module Leaders/markers are encouraged to handle the marking of the assignments electronically if they are received by e-submission, and to mark on-screen. (P1)

In some cases more specific roles, usually of a senior level, have been highlighted in order to assign responsibility for an action, for example the use of 'Heads of Subject' within Policy 3:

Heads of Subject will be responsible for ensuring that all academic staff within a subject area are undertaking e-submission marking and feedback, in accordance with this policy. (P3)

Senior School Registrars and Senior School Administrators will have access rights to modules to enable them to edit information. (P1) 
In terms of support staff, there are 10 different key words in 15 references, showing a diversity of terminology for referring to support staff and support departments. The learning technology/academic enhancement support teams are mentioned in three policies as avenues for further support. The remaining references refer to primarily academic support/administrative staff or departments. In two policies their only mention is related to the benefits for support/administrative staff or to clarify the target audience of the policy. Only Policy 4 actually assigns any actions or responsibilities to support staff:

The Learning and Information Service will provide a printing and delivery service to faculties. (P4)

However Academic Services should be alerted to any emerging issues so that early action can be taken to ensure equality of experience for disabled students (P4)

The role of support/administrative staff is therefore not well documented in the policies, so it is difficult to see what their relevance or power is in the EMA process. It is possible that some of the actions on students may well be the responsibility of support/administrative staff and so the policies should clarify this. For example, one might expect that it is the administrative staff who prepare the module handbook, and as such the following task would come under their responsibility:

Explicit instructions to students on how they should submit a specific item of coursework should be included in the module handbook and also in the online instructions for each submission.

However, it is equally likely that the same role would be the responsibility of a 'Module Leader'. The policies might therefore leave some of the administrative actions deliberately vague due to the different assignment of roles within institutions.

\section{Institution}

The institution, or sections of the institution, such as departments and faculties, can be personified by putting the institution as the active noun in a sentence rather than the people of the institution. Smith (2008) reported that personification of the institution was a common occurrence in learning and teaching strategies and this sort of personification occurred in four of the five EMA policies, for example:

Departments may use e-submission, marking and feedback for projects and dissertations where appropriate. $(P 1)$

[Institution] adopted electronic submission of all appropriate student assignments from September 2011. (P3) 
In submitting student work to Turnitin the University passes personal data (student name only) to a third-party ... (P4)

[Institution] is committed to ensuring students receive clear, legible and constructive feedback within a timely and appropriate manner... (P5)

Policy 4 makes the most references to 'the University' especially in relation to the ownership of policies, for example:

\section{Work marked online will be actioned and returned to students in accordance with the University's Assessment Practice policy. (P4)}

The University's policy on extenuating circumstances will apply to online submission. (P4)

Policy 5 is the only document to make use of a personal pronoun, such as 'we', to refer to the institution's acknowledgement of certain facts:

We recognise the formative nature of Turnitin for students and will ensure that Turnitin is set up in accordance with the University's Turnitin Policy. (P5)

\section{Conclusion}

Policies should speak with authority in order to "legitimate and initiate practices in the world" (Ball, 2012, p. 22). The policies reviewed generally used a median level of authority to indicate expected actions, rather than enforce staff and students to act in a specific way. There are some aspects of the EMA process, such as e-marking, where academic staff express reluctance and so the policies would not be expected to enforce some parts of the process. For example, Ellis and Reynolds (2013) suggested managing the transition to e-marking by allowing staff to continue working using existing practices.

A major theme in each stage of the analysis was the lack of clarity when it came to the actor in a clause. This was more pronounced when it came to actions relating to students. Given Smith (2008) identified the same issue with Learning and Teaching strategies, this was to be expected as it is likely the same people are involved in the writing of both educational strategies and policies. The outcome is that the policies speak more to academic staff than to students and administrative staff and so it would be necessary to provide additional documentation to ensure students and administrative staff know what is expected of them.

Considering the five policies in this review, it is possible to draw up some guidance on the most useful things to include in an EMA policy to ensure clarity. As noted, few UK HE institutions currently have institutional EMA policies (Newland et al., 2013; Walker et al., 2012) and so this guidance would be of benefit 
to institutions who are looking to develop an EMA policy. The guidance is arranged according to the three areas of analysis:

- Structure: The policy document should reflect a formal document through the inclusion of a title page with a clear heading and institutional logo. To benefit the reader, the document should clearly state the author, the date of publication, an approval date and by whom the document was approved. Location of the policy document was not considered here, but this might lend greater formality and authority to the document.

- $\quad$ Language: The policy needs to strike a balance between enforcing language (high modulation) and appearing weak (low modulation). The use of the passive tense, especially with no subject, should be avoided to help to enforce the actions and responsibilities. Where parts of the process are potentially contentious, care must be taken to ensure the language encourages, rather than enforces action so as not to alienate staff who are unsure or uncomfortable about the use of technology.

- Participants: The policy should state the target audience and ensure that the target audience is well represented within the document. In particular, it is important to ensure that students and support/administrative staff are represented through the use of active clauses and clearly defined actions and responsibilities. A policy should use consistent terminology when referring to academic staff and should only use more specific terms such as 'Module Leaders' and 'Heads of Subject' where they assign responsibility for certain tasks or actions. In terms of limitations, this study reviewed five policy documents, however the documents were considered in isolation and their context, such as their location on the institution's website or within institutional documentation was not taken into consideration. This may have provided additional social or cultural clues pertaining to the authority of the document and the intended audience. Future work could explore further the discourse and genre of EMA policy documents, in particular relating to the creation of the policy documents. A text is rarely the work of an individual and so in the creation of a text "discursive differences are negotiated; they are governed by difference in power that is in part encoded in and determined by discourse and genre" (Wodak \& Meyer, 2009a, p. 10). It would be beneficial to understand the processes surrounding the creation of the policy, the role of the individual authors and the consultation carried out with the key stakeholders. In addition, understanding the iterations and revisions of the previous versions would provide insight into the steps for creating policy documents for institutions looking to write their own. 


\section{References}

Ball, S. (2012). Politics and Policy Making in Education. Abingdon, UK: Routlege.

Bancroft, P., Hynd, J., Dal Santo, F., \& Reye, J. (2003). Web-based assignment submission and electronic marking. Paper presented at the 26th Higher Education Research and Development Society of Australasia (HERDSA) Annual Conference, Christchurch, New Zealand.

Bridge, P., \& Appleyard, R. (2008). A comparison of electronic and paper-based assignment submission and feedback. British Journal of Educational Technology, 39(4), 644-650.

Buckley, E., \& Cowap, L. (2013). An evaluation of the use of Turnitin for electronic submission and marking and as a formative feedback tool from an educator's perspective. British Journal of Educational Technology, 44(4), 562-570.

Dahl, S. (2007). Turnitin®: The student perspective on using plagiarism detection software. Active Learning in Higher Education, 8(2), 173-191.

Djordjevic, A., \& Milward, S. (2012). OCME (Online Coursework Management Evaluation) Final Report. http://as.exeter.ac.uk/media/level1/academicserviceswebsite/aboutus/biss/iws/documents/OCMEFinalR eportv1.pdf: Jisc.

Downton, A., Glasfurd-Brown, G., \& Mossop, R. (2006). Online coursework submission from pilot to university-wide implementation: rationale, challenges and further development. Paper presented at the 10th CAA International Computer Assisted Assessment Conference, Loughborough, UK.

Eggins, S. (1994). An Introduction to Systemic Functional Linguistics. London, UK: Pinter Publishers Ltd.

Ellis, C., \& Reynolds, C. (2013). EBEAM Final Report. http://jiscdesignstudio.pbworks.com/w/file/fetch/66830875/EBEAM\%20Project\%20report.pdf: Jisc.

Fairclough, N. (2002). Discourse and Social Change. Cambridge, UK: Polity Press.

Fairclough, N., Mulderrig, J., \& Wodak, R. (2011). Critical Discourse Analysis. In T. Van Dijk (Ed.), Discourse Studies: a multidisciplinary introduction. London, UK: Sage Publications Ltd.

Ferrell, G. (2012). A view of the Assessment and Feedback Landscape: baseline analysis of policy and practice from the JISC Assessment \& Feedback programme. http://www.jisc.ac.uk/whatwedo/programmes/elearning/ /media/A639131E053F49A08EFDDF502CA 7AADA.ashx.

Gray, L., \& Ferrell, G. (2013). Electronic Assessment Management. Retrieved 15 December, 2013, from http://www.jisc.ac.uk/guides/electronic-assessment-management

Jones, D., \& Behrens, S. (2003). Online Assignment Management: An Evolutionary Tale. Paper presented at the 36th Hawaii International Conference on System Sciences (HICSS'03), Big Island, HI, USA.

Luke, A. (2002). Beyond Science and Ideology Critique: Developments in Critical Discourse Analysis. Annual Review of Applied Linguistics, 22, 96-110.

Newland, B., Martin, L., Bird, A., \& Masika, R. (2013). HELF - Electronic Management of Assessment Survey Report 2013. http://w01.helfcms.wf.ulcc.ac.uk/fileadmin/documents/projects/EMAsurveyreport2013.pdf.

Nolan, J., \& Mayfield, W. (2008). A Collaborative Enquiry into Academic Practice: an exploration of the meanings of formative assessment - A Preliminary Critical Discourse Analysis of the Institutional Context. Paper presented at the Society for Research into Higher Education (SRHE) Annual Conference, Liverpool, UK.

Rogers, R., Malancharuvil-Berkes, E., Mosley, M., Hui, D., \& O’Garro Joseph, G. (2005). Critical Discourse Analysis in Education: A Review of the Literature. Review of Educational Research, 75(3), 365-416.

Sharpe, R., Benfield, G., \& Francis, R. (2006). Implementing a university e-learning strategy: levers for change within academic schools. ALT-J, Research in Learning Technology, 14(2), 135-151.

Smith, K. (2008). "Who do you think you're talking to?" - The discourse of learning and teaching strategies. Higher Education, 56(4), 395-406.

Taylor, S. (2004). Researching educational policy and change in 'new times' : using critical discourse analysis. Journal of Education Policy, 19(4), 433-451.

The University of Newcastle Australia. (2013). Definition and Role of Policy. Retrieved 24 November, 2013, from http://www.newcastle.edu.au/service/policy/definition.html

Thomas, S. (2005). The construction of teacher identities in educational policy documents: A critical discourse analysis. Melbourne Studies in Education, 46(2), 25-44. doi: 10.1080/17508480509556423

Van Dijk, T. (1993). Principles of Critical Discourse Analysis. Discourse and Society, 4(2), 249-283.

Walker, R., Voce, J., \& Ahmed, J. (2012). UCISA 2012 Survey of Technology Enhanced Learning for higher education in the UK. from http://www.ucisa.ac.uk/ /media/groups/ssg/surveys/TEL_survey_2012_with\%20Apps_final

Walker, R., Voce, J., \& Jenkins, M. (2013). Charting the development of technology-enhanced learning developments across the UK higher education sector: a longitudinal perspective (2001-2012). Interactive Learning Environments. doi: 10.1080/10494820.2013.867888 
Wodak, R., \& Meyer, M. (2009a). Critical Discourse Analysis: history, agenda, theory and methodology. In R. Wodak \& M. Meyer (Eds.), Methods of Critical Discourse Analysis (Second Edition ed.). London: Sage Publications Ltd.

Wodak, R., \& Meyer, M. (2009b). Methods of Critical Discourse Analysis (Second Edition ed.). London, UK: Sage Publications Ltd.

Yorke, M. (1998). The Management of Assessment in Higher Education. Assessment \& Evaluation in Higher Education, 23(2), 101-116. 